\title{
Sero-prevalence of hepatitis B virus infection and associated factors among health care workers and medical waste handlers in primary hospitals of North-west Ethiopia
}

Endalew Yizengaw ${ }^{1 *}$, Tamyalew Getahun ${ }^{2}$, Mekuanint Geta ${ }^{3}$, Wondemagegn Mulu', Mulat Ashagrie ${ }^{2}$, Derese Hailu ${ }^{4}$ and Shibabaw Tedila ${ }^{5}$

\begin{abstract}
Objective: The aim of this cross-sectional study was to determined the sero-prevalence of HBV infection and associated factors among health care workers and medical waste handlers in primary hospitals of North-west Ethiopia.

Results: A total of 388 study participants were included in this study. Of which, 268 (69\%) were health care workers and 120 (31\%) were medical waste handlers. Males accounted 54.9\% and the mean age for all study participants was 28.3 (standard deviation $=6.9$ ). Hepatitis B virus surface antigen ( $\mathrm{HBsAg}$ ) was detected in $2.6 \%$ health care workers and $2.5 \%$ medical waste handlers and the overall hepatitis B virus infection was 10 (2.6\%). High rate of hepatitis B virus infection was detected in single participants and those in the age group of 30-40 years were more infected (6.6\%). History of contact with $\mathrm{HBV}$ infected case $(8.3 \%)(\mathrm{AOR}=6.8,95 \% \mathrm{Cl}=1.6-28.5, \mathrm{P}=0.009)$ and history of jaundice (15.4\%) $(A O R=10.5,95 \% \mathrm{Cl}=2.1-12.2, \mathrm{P}=0.03)$ were statistically associated factors for HBV infection. More than half (54.4\%) of the study participants did not take training on infection and 9 (4.3\%) of them were positive for $\mathrm{HBs} \mathrm{Ag}$ $(\mathrm{COR}=1.3,95 \% \mathrm{Cl}=0.0 .02-1.02, \mathrm{P}=0.052)$.
\end{abstract}

Keywords: Hepatitis B virus, Health care workers, Medical waste handlers

\section{Introduction}

Hepatitis is a major public health problem commonly transmitted in health care settings that causes significant mortality and morbidity worldwide [1]. It is mainly caused by Hepatitis viruses, including hepatitis B virus (HBV) $[2,3] . \mathrm{HBV}$ is a DNA virus classified under the family Hepadnaviridae. Humans are the only known natural host for HBV. HBV enters the liver via the bloodstream, and replication occurs in the liver tissue [4]. Globally, 2 billion people are infected with HBV of whom about 360 million are chronic carriers [5-10], 50 million people are newly infected every year [9] and over one million people die each year [10]. The situation is

\footnotetext{
*Correspondence: endalew02@gmail.com

${ }^{1}$ Department of Medical Laboratory Science, College of Medicine and Health Sciences, Bahir Dar University, PO Box 79, Bahir Dar, Ethiopia Full list of author information is available at the end of the article
}

more severe in the developing world particularly in Asia and sub-Saharan Africa [7, 11-13]. Insufficient coverage of $\mathrm{HBV}$ vaccination, injection drug users, unsafe blood transfusion, and inadequate health precautions are major risk factors for HBV infection in these regions. [11-13]. World Health Organization (WHO) estimates that the prevalence of HBV infection in Africa is on average more than $10 \%$ [12]. Africa has the second largest number of chronic carriers ( $>8 \%)$ next to Asia [14]. Ethiopia is considered to have medium to high HBV infection rate $[15$, 16].

Although most infections in the developing world occur in childhood and early adulthood, a significant portion of adults remain at risk [17-24]. Hepatitis B virus infection is a recognized occupational hazard as non-immune health care workers $(\mathrm{HCW})$ and medical waste handlers $(\mathrm{MWH})$ who perform invasive procedures and who handle human 
specimens are at high risk of exposure [20-25]. Limited vaccination access and poor preventive practices contribute for the high prevalence of HBV infection [26-31]. On top of these, the existing treatment for HBV infection does not provide a complete cure [30,32]. A protective HBV vaccine has been around since 1982 [30, 31, 33-35]. But HCWs and MWHs in the developing world have poor access to this vaccine [35-39].

Even though few studies had indicated intermediate to high HBV infection in Ethiopia, no sufficient data among HCWs and MWHs. On the other hand, HCWs and MWHs are at high risk of transmitting to the community. This study showed the sero-prevalence of HBV and associated factors among HCWs and MWHs. Besides, this work is used as a benchmark for policy makers and stakeholders. It is also important beyond the country as it adds in the existing knowledge in HBV infection and associated factors.

\section{Main text \\ Methods and materials \\ Study design and period}

A hospital based cross-sectional study was conducted from September 2017 to December 2017. HCWs and MWHs were included from different primary hospitals. The number of HCWs was allocated proportionally to each hospital. Random sampling technique was employed to select HCWs at each hospital and all MWHs were included in the study.

\section{Study area and setting}

This study was conducted at primary government sponsored 50 bed hospitals around Bahir Dar, North-west Ethiopia. These hospitals serve about one million people. Bahir Dar is the capital city of Amhara National Regional State (ANRS), Ethiopia. It is $570 \mathrm{~km}$ away from Addis Ababa, the capital, in the North-west direction and situated in the south of Lake Tana, the biggest lake in the country. The altitude ranges from $1799 \mathrm{~m}$ to 5902 $\mathrm{ft}$ above sea level and the coordinates are $11^{\circ} 35.6184^{\prime} \mathrm{N}$ latitude and $37^{\circ} 23.4462^{\prime} \mathrm{E}$ longitude. There are different HCWs, MWHs and supporting staffs in each hospital. Of whom, HCWs and MWHs have high risk of exposure for various infectious agents like HBV and high possibility of transmitting the infection to clients.

\section{Data collection}

Self-administered structured questionnaire was used to collect socio-demographic characteristics of the study participants and associated risk factors.

\section{Laboratory procedure}

Sample collection Five milliliters of venous blood were collected from each study participant by plane tube (BD Vacutainer) following standard operating procedure for collection of blood. Blood was centrifuged at 300 RPM for at least $10 \mathrm{~min}$ at room temperature and the serum obtained was collected with eppendorf tube. Collected serum was store at $-20{ }^{\circ} \mathrm{C}$ if not processed immediately. The serum sample was used to detect hepatitis B surface antigen.

\section{Detection of hepatitis $B$ virus surface antigen ( $H B s A g$ )}

Tests for the HBV infection can be made by demonstration in sera of specific markers of infection. Screening of hepatitis B surface antigen ( $\mathrm{HBsAg}$ ) was performed for diagnosis of HBV infection in this study. From each collected serum sample HBsAg was tested using an enzyme-linked immuno sorbent assay (ELISA), Hepanostika ELISA kits (Hepanostika HBsAg Uni-Form II, bio-Mérieux, Boxtel, The Netherlands) following the manufacturer protocols.

\section{Quality control}

Blood sample was collected by experienced laboratory practitioners. All the reagents were checked for expiry date, appropriate storage temperature and humidity before use. Positive and negative controls were run together with each sample testing. The ELISA washer was rinsed before every washing procedures and ELISA reader was calibrated before running the test. The detection of HBsAg was done strictly following the manufacturer's instruction. Collected data was checked for completeness and consistencies.

\section{Statistical analysis}

Data were entered and analyzed using Statistical Package for Social Science 22 (IBM Corp- Released 2011. IBM SPSS statistics Armonk, NY: IBM Corp). Descriptive statistics was used to describe the demographic characteristics of participants with HBV infection. Bivariable logistic analysis was used to identify factors associated with HBV infection. A multivariable logistic regression was used to assess the impact of the independent variables on the outcome variable. Odds ratios (OR) was used as a measure of the strength of association and $P$ value $\leq 0.05$ was considered statistically significant.

\section{Results}

Socio-demographic data

A total of $268 \mathrm{HCWs}(69 \%)$ and $120 \mathrm{MWHs}(31 \%)$ were participated in this study. Males accounted $54.9 \%$ and 
the mean age for all study participants was 28.3 (standard deviation $=6.9$ ) and the minimum and maximum age was 19 and 54 years respectively. Majority (94.8\%) of the participants were orthodox Christians. Regarding the marital status of participants about $49 \%$ were single and $45.1 \%$ were married. Among HCWs participated in the study, $45.9 \%$ were nurses (including midwifes) and 9.3\% were doctors (including emergency surgeries). Laboratory practitioners and pharmacists accounted 8 and $5.9 \%$ respectively (Table 1 ).

\section{Sero-prevalence of hepatitis B virus infection}

From the total $268 \mathrm{HCWs}$ and $120 \mathrm{MWHs}$ screened for hepatitis B surface antigen, 7 (2.6\%) and $3(2.5 \%)$ were positive respectively and the overall hepatitis $B$ virus infection was $10(2.6 \%)$. High rate of hepatitis B virus infection was detected in single participants and those in the age group of 30-40 years were more infected (6.6\%). Increased proportion of $\mathrm{HBV}$ was detected in males $(\mathrm{OR}=1.2,95 \% \mathrm{CI}=0.35-4.3, \mathrm{P}=0.75)$, Age group $30-40$ $(\mathrm{OR}=1.1,95 \% \mathrm{CI}=0.10-12.7, \mathrm{P}=0.93)$ but it was not statistically significant (Table 2 ).

Table 1 Socio-demographic characteristic of health care workers and medical waste handlers in primary hospitals around of North-west Ethiopia, 2018

\begin{tabular}{lcl}
\hline Variables & Frequencies & Percentage (\%) \\
\hline Age (years) & 280 & 72 \\
$21-29$ & 76 & 19.6 \\
$30-40$ & 29 & 7.5 \\
$41-50$ & 3 & 8 \\
+50 & & \\
Gender & 175 & 54.9 \\
Male & 213 & 45.1 \\
Female & & \\
Religion & 368 & 94.8 \\
Orthodox & 18 & 4.6 \\
Muslim & 2 & 0.5 \\
Others & & \\
Marital status & 190 & 49 \\
Single & 175 & 45.1 \\
Married & 5 & 1.3 \\
Divorced & 6 & 1.5 \\
Widowed & 12 & 3.1 \\
Separated & & \\
Occupation & 178 & 45.9 \\
Nurse & 36 & 9.3 \\
Doctor & 31 & 8.9 \\
Laboratory & 23 & \\
Pharmacy & 120 & \\
Medical waste handler & & \\
\hline
\end{tabular}

Table 2 Demographic characteristics and hepatitis B virus infection among health care workers and medical waste handlers in primary hospitals around of North-west Ethiopia, 2018

\begin{tabular}{lclll}
\hline Variables & N (\%) & \multicolumn{3}{l}{ HBsAg (N=388) } \\
\cline { 3 - 5 } & & $\mathbf{n}(\%)$ & COR (95\% Cl) & P value \\
\hline Sex & & & & \\
Male & $175(45.1)$ & $5(2.9)$ & $1.2(0.35-4.3)$ & 0.75 \\
Female & $213(54.9)$ & $5(2.3)$ & 1 & \\
Age & & & & \\
$19-29$ & $280(72.2)$ & $7(2.5)$ & $1.2(0.15-10)$ & 0.85 \\
$30-40$ & $76(19.6)$ & $2(2.7)$ & $1.1(0.10-12.7)$ & 0.93 \\
$\geq 41$ & $32(8.2)$ & $1(3.0)$ & 1 & \\
Marital status & & & & \\
Single & $190(49.0)$ & $6(3.2)$ & 1 & \\
Married & $175(45.1)$ & $3(1.7)$ & $1.9(0.46-7.6)$ & 0.38 \\
Divorced & $23(5.9)$ & $1(4.3)$ & $0.72(0.08-6.2)$ & 0.76 \\
Profession & & & & \\
$\quad$ Nurse + Doctor & $214(55.2)$ & $4(1.9)$ & 1 & 0.15 \\
Laboratory & $31(8)$ & $2(6.5)$ & $0.23(0.05-1.6)$ & 0.15 \\
Pharmacy & $23(5.9)$ & $1(4.3)$ & $0.42(0.04-3.9)$ & 0.45 \\
Medical waste handler & $120(30.9)$ & $3(2.5)$ & $0.74(0.16-3.4)$ & 0.70 \\
\hline
\end{tabular}

\section{Associated factors for hepatitis B virus infection}

The following associated factors [11-13] were assessed for hepatitis B virus infection: history of blood transfusion, history of circumcision, history of jaundice, history of needlestick injury vaccination status, history of hospitalization, history of unprotected sex, history of previous dental and surgical procedures, history of contact history and training status were some of the factors. Of which, history of jaundice and history of contact with HBV infected case had independent and statistically significant association with multivariable logistic regression. It was showed that $26(6.7 \%)$ and 80 (20.6) study participants had a history of jaundice and multi-sex partner respectively. Of the total study participants only 36 (9.3\%) were vaccinated for HBV and $60(15.5 \%)$ had history of contact with HBV infected case. There were $24(6.2 \%)$ study participants who had history of sharing dental materials during dental procedures. Among those who had a history of contact with HBV infected case, 5 (8.3\%) were positive for $\mathrm{HBsAg}$ and this was statistically significant (AOR $=6.8,95 \%$ $\mathrm{CI}=1.6-28.5, \mathrm{P}=0.009)$. Three $(12.5 \%)$ of participants with history of sharing dental materials during dental procedures were positive for $\mathrm{HBsAg}(\mathrm{AOR}=4.0,95 \%$ CI, 0.81-20.4, $\mathrm{P}=0.09$ ). Among those who had history of jaundice, four (15.4\%) were positive for $\mathrm{HBsAg}$ $(\mathrm{AOR}=10.5,95 \% \mathrm{CI}=2.1-12.2, \mathrm{P}=0.004)$ and $5(6.2 \%)$ of the study participants who had multi-sex partner 
were positive for $\mathrm{HBsAg}(\mathrm{AOR}=1.5,95 \% \mathrm{CI}=0.33-$ $6.6, \mathrm{P}=0.60$ ).

More than half (54.4\%) of the study participants did not take training on infection prevention protocols of various infectious diseases including HBV and 9 (4.3\%) of them were positive for $\mathrm{HBsAg}(\mathrm{COR}=1.3,95 \% \mathrm{CI}=0.0 .02$ $1.02, \mathrm{P}=0.052)$ (Table 3$)$.

\section{Discussion}

This study showed the prevalence of HBV infection among HCWs and MWHs at primary hospitals. Though HBV infection is preventable and there is a protective vaccine, it remains a public health problem world-wide especially in Africa where Ethiopia is no exception. HCW and MWH are among high risk groups for infectious disease including HBV. Estimates of HBV infection among $\mathrm{HCW}$ and $\mathrm{MWH}$ are needed to know the disease burden and thus to establish protective strategies. Yet limited data is available on the sero-prevalence of HBV infection in this risk groups in Ethiopia. Hepatitis $B$ virus infection can be diagnosed by detecting different markers associated with the virus and/or with the immune response. In the present study we use HBsAg as a marker of infection to diagnose $\mathrm{HBV}$ infection.

The present study had shown that HBsAg was detected in $2.6 \%$ of HCWs and $2.5 \%$ MWHs with overall prevalence of $2.6 \%$. The sero-prevalence of HBV in HCWs in this study was higher than the study conducted in tertiary hospital of Indian $\mathrm{HCW}(0.4 \%)$. This difference could be due to the low vaccination coverage and shortage of training on infection prevention in Ethiopia. In this study we found that only $36(9.3 \%)$ of the $\mathrm{HCW}$ and MWH were vaccinated against hepatitis B virus. This is much lower than the report in India where $50 \%$ of $\mathrm{HCW}$ were fully vaccinated and the WHO hepatitis $\mathrm{B}$ vaccine coverage estimate in African $\mathrm{HCW}$ where the lowest is $18 \%[12,38]$. The detection of HBsAg among MWHs in the present study was lower than the report from southern Ethiopia (1.3\%) where $7.2 \%$ of participants were vaccinated against HBV [39].

However, the detection rate of HBsAg in MHWs and HCWs was lower than previous studies conducted in Addis Ababa (6.3\%) and Gondar (6.0\%) [40, 41] and in

Table 3 Hepatitis B virus infection and associated factors among health care workers and medical waste handlers in primary hospitals around of North-west Ethiopia, 2018

\begin{tabular}{|c|c|c|c|c|c|c|c|}
\hline Variables & & $N(\%)$ & $\begin{array}{l}\text { HBsAg positive } \\
\text { n (\%) }\end{array}$ & COR $(95 \% \mathrm{Cl})$ & $P$ value & AOR $(95 \% \mathrm{CI})$ & $P$ value \\
\hline \multirow[t]{2}{*}{ Transfusion } & Yes & $128(33)$ & $4(3.1)$ & $1.4(0.38-4.9)$ & 0.63 & & \\
\hline & No & $260(67)$ & $6(2.3)$ & 1 & & & \\
\hline \multirow[t]{2}{*}{ Circumcision } & Yes & $256(66)$ & $8(3.1)$ & $2.1(0.44-10)$ & 0.53 & & \\
\hline & No & $132(34)$ & $2(1.5)$ & 1 & & & \\
\hline \multirow[t]{2}{*}{ Jaundice } & Yes & $26(6.7)$ & $4(15.4)$ & $10.8(2.8-41)$ & $<0.001$ & $10.5(2.1-12.2)$ & 0.004 \\
\hline & No & $362(93.3)$ & $6(1.7)$ & 1 & & & \\
\hline \multirow[t]{2}{*}{ Needlestick injury } & Yes & $72(18.6)$ & $2(2.8)$ & $1.1(0.23-5.3)$ & 0.90 & & \\
\hline & No & $316(81.4)$ & $8(2.5)$ & 1 & & & \\
\hline \multirow[t]{2}{*}{ Lack of vaccination } & Yes & $36(9.3)$ & $1(2.8)$ & 1 & & & \\
\hline & No & $352(90.7)$ & $9(2.6)$ & $1.1(0.13-8.8)$ & 0.94 & & \\
\hline \multirow[t]{2}{*}{ Hospitalization } & Yes & $123(31.7)$ & $5(4.1)$ & $2.2(0.63-7.7)$ & 0.22 & & \\
\hline & No & $265(68.3)$ & $5(1.9)$ & 1 & & & \\
\hline \multirow[t]{2}{*}{ Surgical procedures } & Yes & $64(15.5)$ & $2(3.1)$ & $1.3(0.26-6.1)$ & 0.63 & & \\
\hline & No & $324(84.5)$ & $8(2.5)$ & 1 & & & \\
\hline \multirow[t]{2}{*}{ Unprotected sex } & Yes & $103(26.5)$ & $5(4.9)$ & $2.8(0.8-10)$ & 0.10 & & \\
\hline & No & $285(73.5)$ & $5(1.8)$ & 1 & & & \\
\hline \multirow[t]{2}{*}{ Multi-sex partner } & Yes & $80(20.6)$ & $5(6.2)$ & $4(1.1-14)$ & 0.03 & $1.5(0.33-6.6)$ & 0.60 \\
\hline & No & 308 (79.4) & $5(1.6)$ & 1 & & & \\
\hline \multirow[t]{2}{*}{ Dental procedures } & Yes & $24(6.2)$ & $3(12.5)$ & $7.3(1.7-30)$ & 0.006 & $4.0(0.81-20.4)$ & 0.09 \\
\hline & No & $364(93.8)$ & $7(1.9)$ & 1 & & & \\
\hline \multirow[t]{2}{*}{ Contact history } & Yes & $60(15.5)$ & $5(8.3)$ & $5.9(1.6-20.9)$ & 0.006 & $6.8(1.6-28.5)$ & 0.009 \\
\hline & No & $328(84.5)$ & $5(1.5)$ & 1 & & & \\
\hline \multirow[t]{2}{*}{ Training } & Yes & $177(45.6)$ & $1(0.6)$ & 1 & & & \\
\hline & No & $211(54.4)$ & $9(4.3)$ & $1.3(0.02-1.02)$ & 0.052 & & \\
\hline
\end{tabular}


Sudan (4.4\%), Tanzania (7.4\%) and Uganda (8.1\%) [4244] respectively. Only $20 \%$ of HCWs in Tanzania were vaccinated and none of the MWHs in Gondar and HCWs in Sudan was vaccinated for HBV and there might be improvements in awareness on safety procedures and the importance of vaccination.

The occupational risk of HBV infection in this study was high for the laboratory practitioners and MWHs. This indicates that there is a difference in level of risk of exposure for HBV infection among different professions. Similar result had been reported from Uganda $[43,44]$. Still there is no regular and programmed protective vaccination program against HBV in Ethiopia for high risk groups like HCWs and MWHs. Indeed this study show that individuals with no training in infection prevention had a higher risk of exposure (though not significant) to hepatitis B virus infection [43, 44]. In this study, a statistically significant association was observed between HBV infection and history of jaundice $(\mathrm{P}=0.004)$ and history of contact with HBV positive cases $(P=0.009)$. This signifies that jaundice can be considered as a suggestive indicator for HBV infection so that further diagnosis with specific tests is required to rule out other infections and health conditions.

Though there is no concert national prevalence data [45] to discuss with, the detection rate of HBsAg in MHWs and HCWs in this study was lower than reports from population based studies in the country. A five decade (1968-2015) systematic and meta-analysis study conducted in Ethiopia showed a pooled prevalence of $7.4 \%$ [45]. In the same study, higher prevalence of HBsAg is reported among HCW (7.3-9.0\%) and medical MWH (6.0-6.3\%). A community based cross-sectional study showed 3.1\% HBV prevalence by detecting HBsAg [46]. This might be due to the decline in the prevalence of HBV infection in the country. The relative improvement in the accessibility of the protective vaccine and awareness regarding the prevention of the disease might contribute in the reduction of the HBV infection. On the other hand it might indicate that working in the hospital seething might be protective against HBV. It is plausible that those who are working in the hospital get trainings on the prevention of infectious disease more frequent than the community. They are also given a priority in vaccination as they are considered as risk groups since they deal with sort of infected sample. Most importantly the level of education and their field of specialty, especially for health care workers, are also better than the community [ 45 , 46] so that they have expected to have better awareness regarding the precautions and safety of blood borne transmission in general and HBV infection prevention in particular.

\section{Conclusion}

The occupational risk of $\mathrm{HBV}$ infection among the HCWs and MWHs in this study was high. HBV vaccine and trainings on infection prevention should be more readily available for these high risk groups.

\section{Limitations of the study}

This study didn't determine other potential infectious pathogens in health care settings like hepatitis $\mathrm{C}$ virus and HIV.

\section{Abbreviations \\ DNA: deoxyribonucleic acid; ELISA: enzyme linked immuno sorbent assay; HBsAg: hepatitis B surface antigen; HBV: hepatitis B virus; WHO: World Health Organization.}

\section{Authors' contributions}

EY conceived the idea, participated in the data collection, data analysis and drafted the manuscript. TG, WM, MA, MG, DH and ST participated in data analysis, data collection, reviewed the manuscript and approved for publication. All authors read and approved the final manuscript.

\section{Author details \\ ${ }^{1}$ Department of Medical Laboratory Science, College of Medicine and Health Sciences, Bahir Dar University, PO Box 79, Bahir Dar, Ethiopia. ${ }^{2}$ Addis Alem Hospital, Bahir Dar, Ethiopia. ${ }^{3}$ Department of Medical Microbiology, School of Biomedical and Laboratory Sciences, College of Medicine and Health Sci- ences, University of Gondar, Gondar, Ethiopia. ${ }^{4}$ Amhara Public Health Institute, Bahir Dar, Ethiopia. ${ }^{5}$ Department of Human Anatomy, College of Medicine and Health Sciences, Bahir Dar University, Bahir Dar, Ethiopia.}

\section{Acknowledgements}

We would like to express our deepest gratitude to the study participants for their volunteer participation in this research work. Our heartfelt gratitude goes to Amhara Public Health Institute that reviewed this research and secures ethical clearance.

\section{Competing interests}

The authors declare that they have no competing interests.

Availability of data and materials

The datasets analyzed during this study are available from the corresponding author on reasonable request.

\section{Consent for publication \\ Not applicable.}

\section{Ethics approval and consent to participate}

This study was approved by Amhara Public Health Institute Research Review Committee (the former Amhara Regional Laboratory) (Ref Re/TS/ RTT/01/646/09). Written informed consent was obtained from each study participants before administration of questioner and sample collection. In addition, support letter was secured from each respective hospital. HBsAg positive results were communicated to physicians for proper management. Personal identifiers were not used and data were retrieved only for the study purpose to insure confidentiality. Moreover, the results of this study have been submitted to Amhara Public Health Institute, study hospitals and other stakeholders and recommended them to provide regular preventive vaccines and trainings on infection prevention.

\section{Funding}

This study was not funded by any organization.

\section{Publisher's Note}

Springer Nature remains neutral with regard to jurisdictional claims in published maps and institutional affiliations. 
Received: 4 April 2018 Accepted: 26 June 2018

Published online: 03 July 2018

\section{References}

1. Ryder S, Beckingham I. ABC of diseases of liver, pancreas, and biliary system: acute hepatitis. Br Med J. 2001;322:151-3.

2. Gunn RA, Murray PJ, Ackers ML, Hardison WG, Margolis HS. Screening for chronic hepatitis $B$ and $C$ virus infections in an urban sexually transmitted disease clinic: rationale for integrating services. Sex Transm Dis. 2001;28(3):166-70

3. Lok A. Chronic hepatitis B. Natl Engl J Med Sci. 2002;346:1682-3.

4. Shepard W, Simard P, Finelli L, Fiore E, Bell P. Hepatitis B virus infection: epidemiology and vaccination; Atlanta, USA. Epidemiol Rev. 2006;28:112-25.

5. Zhang W, Yin J, Li T. Risk factors for acute hepatitis B and its progression to chronic hepatitis in Shanghai, China. Biomed J. 2008;57:1713-20.

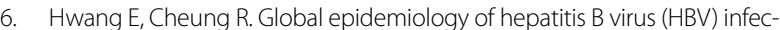
tion. NAJMS. 2011:4:7-13.

7. Merican I, Guan R, Amarapuka D, Alexander M, Chutaputt A, Chien R, et al. Chronic hepatitis B virus infection in Asian countries. Malaysia J Gastroenterol Hepatol. 2000;15:1356-61.

8. Kane M. Global programme for control of hepatitis B infection. Vaccine. 1995:13:47-9.

9. Kane A, Lloyd J, Zaffran M, Simonsen L, Kane M. Transmission of hepatitis B, hepatitis $C$ and human immunodeficiency viruses through unsafe injections in the developing world: model-based regional estimates. Bull World Health Organ. 1999;77(10):801-7.

10. Custer B, Sullivan SD, Hazlet TK, Iloeje U, Veenstra DL, Kowdley KV. Global epidemiology of hepatitis B virus. J Clin Gastroenterol. 2004;38:158-68.

11. Goldstein ST, Zhou F, Hadler SC, Bell BP, Mast EE, Margolis HS. A mathematical model to estimate global hepatitis B disease burden and vaccination impact. Int J Epidemiol. 2005:34(6):1329-39.

12. World Health Organization (WHO). Hepatitis B. Geneva: World Health Organization, Department of Communicable Disease Surveillance and Response 2002

13. Bwogi J, Braka F, Makumbi I, Mishra V, Bakamutumaho B, Nanyunja M, Opio A, Downing R, Biryahwaho B, Lewis RF. Hepatitis B infection is highly endemic in Uganda: findings from a national sero-survey. Afr Health Sci. 2009;9(2):98-108

14. Alavian M, Masoud H, Asl A, Ali K, Lankarani B. Hepatitis B virus infection in Iran. Soc Inf Disp. 2008;8(4):281-94

15. Bosch F, Ribes J, Díaz M, Cléries R. Primary liver cancer: worldwide incidence and trends. Gastroenterology. 2004;127:5-16.

16. Abebe A, Nokes D, Dejene A, Enquselassie F, Messele T, Cutts F. Sero-epidemiology of hepatitis B virus in Addis Ababa, Ethiopia: transmission patterns and vaccine control. Epidemiol Infect. 2003;131(1):757-70.

17. Ageely H, Mahfouz M, Gaffar A, Elmakki E, Elhassan I, Yasin A, Bani I. Prevalence and risk factors of hepatitis B virus in Jazan Region, Saudi Arabia. Health Sci Publ. 2015;7:459-65.

18. Juszczyk J. Clinical course and consequences of hepatitis B infection. Vaccine. 2000;18:23-5.

19. West DJ. The risk of hepatitis $B$ infection among health professionals in the United States: a review. Am J Med Sci. 1984;287(2):26-33.

20. Taylor R, Sladden T, Levy S, Gust I, Macaskill P, Rushworth L, Gaxibarich G. Asero-epidemiological study of hepatitis B amongst Fiji health care workers. Southeast Asian JTrop Med Public Health. 1991;22(4):567-76.

21. Iserson KV, Criss EA. Hepatitis B prevalence in emergency physicians. Ann Emerg Med. 1985;14(2):119-22.

22. Pruss-Ustun A, Rapiti E, Hutin Y. Estimation of the global burden of disease attributable to contaminated sharps injuries among health care workers. Am J Ind Med. 2005;48(6):482-90.

23. Daw MA, Siala IM, Warfalli MM, Muftah MI. Sero-epidemiology of hepatitis $B$ virus markers among hospital health care workers. Analysis of certain potential risk factors. Saudi Med J. 2000;21(12):1157-60

24. Karpuch J, Scapa E, Eshchar J, Waron M, Bar-Shany S, Shwartz T. Vaccination against hepatitis B in a general hospital in Israel: antibody level before vaccination and immunogenicity of vaccine. Isr J Med Sci. 1993;29(8):449-52.
25. Newsom DH, Kiwanuka JP. Needle-stick injuries in an Ugandan teaching hospital. Ann Trop Med Parasitol. 2002;96(5):517-22.

26. Olubuyide IO, Ola SO, Aliyu B, Dosumu OO, Arotiba JT, Olaleye OA, Odaibo GN, Odemuyiwa SO, Olawuyi F. Hepatitis B and C in doctors and dentists in Nigeria. Qjm. 1997:90(6):417-22.

27. Ottoni CM, Penna FJ, Oliveira CG, Souza CJ. Prevalence of serologic markers of hepatitis B in dentistry students and dentists in BeloHorizonte, Brazil. Bol Oficina Sanit Panam. 1995;118(2):108-14.

28. Talaat M, Kandeel A, El-Shoubary W, Bodenschatz C, Khairy I, Oun S, Mahoney FJ. Occupational exposure to needlestick injuries and hepatitis $B$ vaccination coverage among health care workers in Egypt. Am J Infect Control. 2003;31(8):469-74.

29. Lavanchy D. Hepatitis B virus epidemiology, disease burden, treatment, and current and emerging prevention and control measures. J Viral Hepat. 2004;11(2):97-107.

30. Szmuness W, Stevens CE, Harley EJ, Zang EA, Taylor PE, Alter HJ. The immune response of healthy adults to a reduced dose of hepatitis $B$ vaccine. J Med Virol. 1981:8(2):123-9.

31. Treatment Action Group (TAG). Guide to hepatitis B for people living with HIV. New York: TAG; 2009.

32. Tsega E, Mengesha B, Hansson B, Lindberg J, Nordenfelt E. Hepatitis A, B, and delta infection in Ethiopia: a serologic survey with demographic data. Am J Epidemiol. 1986;123(2):344-51.

33. Szmuness W, Stevens CE, Zang EA, Harley EJ, Kellner A. A controlled clinical trial of the efficacy of the hepatitis B vaccine (Heptavax B). Hepatology. 1981;1(5):377-85.

34. Nasir K, Khan KA, Kadri WM, Salim S, Tufail K, Sheikh HZ, Ali SA. Hepatitis B vaccination among health care workers and students of a medical college. J Pak Med Assoc. 2000:50(7):239-43.

35. Mahoney FJ, Stewart K, Hu H, Coleman P, Alter MJ. Progress toward the elimination of hepatitis B virus transmission among health care workers in the United States. Arch Intern Med. 1997;157(22):2601-5.

36. Doebbeling BN, Ferguson KJ, Kohout FJ. Predictors of hepatitis B vaccine acceptance in health care workers. Med Care. 1996;34(1):58-72

37. Braka F, Nanyunja M, Makumbi I, Mbabazi W, Kasasa S, Lewis RF. Hepatitis B infection among health workers in Uganda: evidence of the need for health worker protection. Vaccine. 2006;24(47-48):6930-7.

38. Singha $V$, Bora $D$, Singh S. Prevalence of hepatitis B virus infection in healthcare workers of a tertiary care centre in india and their vaccination status. $J$ Vaccines Vaccin. 2011:2(2):1-4

39. Amsalu A, Worku M, Tadesse E, Shimelis T. The exposure rate to hepatitis B and $C$ viruses among medical waste handlers in three government hospitals, southern Ethiopia. Epidemiol Health. 2016;38:1-8.

40. Shiferaw $Y$, Abebe T, Mihret A. Hepatitis B virus infection among medical waste handlers in Addis Ababa, Ethiopia. Res Notes. 2011:4:479.

41. Anagaw B, Shiferaw Y, Anagaw B, Belyhun Y, Erku W, Biadgelegn F, Moges B, Alemu A, Moges F, Mulu A. Seroprevalence of hepatitis B and C viruses among medical waste handlers at Gondar town health institutions, Northwest Ethiopia. BMC Res Notes. 2012;5:55.

42. Abdalwhab M, Nafi M. Sero-frequency of hepatitis B infection among health care workers in Khartoum. Am J Res Commun. 2014:2(12):148-54

43. Mueller A, Stoetter L, Kalluvya S, Stich A, Majinge C, Weissbrich B, Kasang C. Prevalence of hepatitis B virus infection among health care workers in a tertiary hospital in Tanzania. BMC Infect Dis. 2015;15:386.

44. Ziraba AK, Bwogi J, Namale A, Wainaina CW, Mayanja-Kizza H. Seroprevalence and risk factors for hepatitis B virus infection among health care workers in a tertiary hospital in Uganda. BMC Infect Dis. 2010;10:191.

45. Belyhun Y, Maier M, Mulu A, Diro E, Liebert UG. Hepatitis viruses in Ethiopia: a systematic review and meta-analysis. BMC Infect Dis. 2016;16(761):1-14.

46. Abera B, Adem Y, Yimer M, Mulu W, Zenebe Y, Mekonnen Z. Community seroprevalence of hepatitis B, C and human immunodeficiency virus in adult population in gojjam zones, northwest Ethiopia. Virol J. 2017;14(21):2-5. 